Please do not remove this page

RMIT

UNIVERSITY

\title{
Sound transmission of cavity walls due to structure borne transmission via point and line connections
}

Davy, John

https://researchrepository.rmit.edu.au/esploro/outputs/9921858346701341/filesAndLinks?institution=61RMIT_INST\&index=null

Davy, J. (2012). Sound transmission of cavity walls due to structure borne transmission via point and line connections. Journal of the Acoustical Society of America, 132(2), 814-821.

https://doi.org/10.1121/1.4733533

Document Version: Accepted Manuscript

Published Version: https://doi.org/10.1121/1.4733533

Repository homepage: https://researchrepository.rmit.edu.au

(c) 2012 Acoustical Society of America

Downloaded On 2023/04/26 15:32:25 +1000

Please do not remove this page 
Davy, J 2012, 'Sound transmission of cavity walls due to structure borne transmission via point and line connections', Journal of the Acoustical Society of America, vol. 132, no. 2, pp. 814-821.

Sound transmission of cavity walls due to structure borne transmission via point and line connections $^{\mathrm{a}}$

John L. Davy ${ }^{\text {bc }}$

School of Applied Sciences, RMIT University, GPO Box 2476V Melbourne, Victoria 3001, Australia

Running title: Transmission via point and line connections

a Portions of this work were presented in "Predicting the sound transmission of double leaf cavity walls due to point and line connections," Euronoise 2012, Prague, Czech Republic, 10-13 June 2012.

${ }^{\mathrm{b}}$ Author to whom correspondence should be addressed. Electronic mail: john.davy@rmit.edu.au ${ }^{\mathrm{c}}$ Current address: CSIRO Materials Science and Engineering, PO Box 56 Highett Victoria 3190, Australia. 
The author has published equations for predicting the air borne sound transmission of double leaf cavity walls due to the structure borne sound transmission across the air cavity via (possibly resilient) line connections, but he has never published the full derivation of these equations. He also derived equations for the case when the connections are rigid point connections but has never used them or published them or their derivations. This paper will present the full derivation of the author's theory of the air borne sound transmission of double leaf cavity walls due to the structure borne sound transmission across the air cavity via point or line connections which are modelled as four pole networks. The theoretical results will be compared with experimental results on wooden stud cavity walls from the National Research Council of Canada because the screw spacing is given for these results. This enables connections via studs and screws to be modelled as point connections and avoids the need to make any assumptions about the compliance of the equivalent point or line connections.

PACS numbers: 43.55.Rg, 43.55.Ti, 43.40.Rj, 43.20.Rz 


\section{INTRODUCTION}

The author (Davy, 1990a; b; 1991; 1993) developed and published in conference proceedings formulae for predicting the air borne sound transmission of cavity walls due to line connections between the two wall leaves. These formulae were later published in the learned journal literature (Davy, 2009; Davy, 2010). Unfortunately size limitations on the above papers precluded the author from publishing his full derivation of these formulae. Although the author also developed formulae for the case of rigid point connections at the same time, he has never previously published these formulae because the experimental results, which he was comparing with, did not usually give the screw spacing and may have in fact been made on glued walls. It is now considered timely to publish the full derivation of the author's air sound transmission via structural connections formulae, including modelling the connections as four pole networks.

The reader is referred to the previously cited references and Davy et al. (2012) for a discussion of the work of some other researchers in this area. Other research in this area includes Lin and Garrelick (1977), Craik and Smith (2000b; a), Brunskog (2005), Wang et al. (2005), Legault and Atalla (2009; 2010), Vigran (2010a; b) and Campolina et al. (2012). Vér (1971) and Takahashi (1983) study the structure borne sound transmission through a cavity wall. A number of these authors make use of the spatial periodicity of the point or line connections across the wall cavity which is not used in this paper.

The author's earlier comparisons between the line connection theory and experimental results for wooden stud gypsum plaster board cavity walls with sound absorbing material in the cavity (Davy, 1990a; b; 1993) showed that the theory over estimated the sound insulation in the frequency range from $315 \mathrm{~Hz}$ to 1600 or $2000 \mathrm{~Hz}$. Thus there was no incentive to use the point connection theory which was expected to give even higher results. Furthermore the screw 
spacing was not given and the test specimens may well have been glued along the length of the studs.

Thus it was a surprise when comparisons (Davy, 2009), with more recent measurements by the National Research Council of Canada (NRCC), which gave the screw spacing, showed that the theory under estimated the sound insulation. Agreement (Davy, 2010) was only obtained by increasing the damping loss factor to an unrealistic value of 0.1 which over estimated the earlier experimental measurements. The results of these comparisons suggested that the use of the point connection theory was worthwhile considering again.

\section{COMMON THEORY}

This section develops common theory which will be applied to point connections in section III and line connections in section IV. This paper assumes that the system behaves in a linear fashion and that oscillating quantities are uncorrelated so that they can be combined in the amplitude squared (energy) domain. It assumes that the point and line connections couple only transverse velocities and transverse forces and that they do not couple angular velocities and moments. It ignores the spatial periodicity of the point and line connections between the two wall leaves and the backwards flow of energy from the second wall leaf to the first wall leaf. This paper gives the detailed theory for the air borne sound transmission across the cavity wall due to structure borne sound transmission across the wall cavity via the point or line connections between the two wall leaves. The air borne sound transmission across the wall cavity is added as a separate uncorrelated path using the theory given in Davy (2010). It will be seen in Section V that this last approach is not adequate at low frequencies for gypsum plaster board cavity walls with wooden studs. 
The theory given in this paper differs from Sharp's theory (Sharp, 1973; 1978; Sharp et al., 1980) by integrating over the angle of incidence of the exciting diffuse field sound instead of dividing the mass per unit area of the wall leaves by 1.9, and by replacing Sharp's empirical correction factor of $5 \mathrm{~dB}$ with the effects of the resonant vibration of the wall leaves. This paper also extends the theory to frequencies at and above the critical frequencies of the wall leaves and allows the connections to be modelled as four pole networks. It differs from Vigran's theory (Vigran, 2010b; a) by assuming that the frequency is small compared to the critical frequency when calculating the radiation of an infinite version of the second wall leaf due to the structural connection acting on it and correcting for this by including the resonant radiation of the finite version of the wall leaf.

In this paper oscillating quantities will be described by their root mean square amplitudes rather than by their peak values. Consider the situation of two wall leaves $(i=1$ or 2$)$ with mass per unit area $m_{i}$, angular critical frequencies $\omega_{c i}$, critical frequencies $f_{c i}$, resonant radiation efficiencies $\sigma_{i}$, total damping loss factors $\eta_{i}$ and point or line admittances or mobilties of $Y_{i}$, which are joined by point or parallel line connections. For the case of parallel line connections it will be assumed that the bending waves in the wall leaves are incident normally on the parallel line connections. The junction of the connections with the $i$ th wall leaf will have velocities $v_{i}$, which are assumed to be the same for all connections and, because of the assumption of normal incidence, are the same along the length of each parallel line connection. Each point connection will exert a force $F_{2}$ on the second wall leaf and the first wall leaf will exert a force $F_{1}$ on each point connection. Each line connection will exert a force per unit length $F_{2}$ on the second wall leaf and the first wall leaf will exert a force per unit length $F_{1}$ on each line connection. Again 
because of the assumption of normal incidence, the forces per unit length will be the same along the length of each parallel line connection.

Following Legault and Atalla (2010) and Campolina et al. (2012), the connections will be modelled as a linear four pole system.

$$
\left[\begin{array}{l}
F_{1} \\
v_{1}
\end{array}\right]=\mathbf{T}\left[\begin{array}{l}
F_{2} \\
v_{2}
\end{array}\right]=\left[\begin{array}{ll}
T_{11} & T_{12} \\
T_{21} & T_{22}
\end{array}\right]\left[\begin{array}{l}
F_{2} \\
v_{2}
\end{array}\right] .
$$

For a rigid connection

$$
\mathbf{T}=\left[\begin{array}{ll}
1 & 0 \\
0 & 1
\end{array}\right]
$$

For a massless resilent connection

$$
\mathbf{T}=\left[\begin{array}{cc}
1 & 0 \\
j \omega C & 1
\end{array}\right]
$$

where $\omega=2 \pi f$ is the angular frequency, $f$ is the frequency, the oscillating quantities vary with time as $e^{j \omega t}$ where $t$ is the time variable and $C$ is the compliance of the connection. In the case of a line connection, $C$ has the dimensions of length/(force/length) $=1 /$ pressure. For a point connection, $C$ has dimensions of length/force. For a rigid connection with mass

$$
\mathbf{T}=\left[\begin{array}{cc}
1 & j \omega M \\
0 & 1
\end{array}\right],
$$

where $M$ is the mass of the connection. In the case of a line connection, $M$ has the dimensions of mass/length. For a point connection, $M$ has dimensions of mass.

If the connector is modelled as the series combination of a mass $M_{1}$, compliance $C$ and mass $M_{2}$ then (Campolina et al., 2012)

$$
\mathbf{T}=\left[\begin{array}{cc}
1-\omega^{2} C M_{1} & j \omega\left(M_{1}+M_{2}-\omega^{2} C M_{1} M_{2}\right) \\
j \omega C & 1-\omega^{2} C M_{2}
\end{array}\right]
$$


Equation (5) reduces to equation (3) if $M_{1}=M_{2}=0$, to equation (4) if $C=0$ and to equation (2) if $M_{1}=M_{2}=C=0$. Campolina et al. (2012) introduced damping into the connector by dividing the compliance $C$ by $1+j \eta_{c}$ where $\eta_{c}$ is the damping loss factor of the connector.

The velocity of the second wall leaf at the connection is

$$
v_{2}=Y_{2} F_{2} \text {. }
$$

Equations (1) and (6) give

$$
F_{1}=\left(T_{11}+T_{12} Y_{2}\right) F_{2}
$$

and

$$
v_{1}=\left(T_{21}+T_{22} Y_{2}\right) F_{2}
$$

Equations (7) and (8) give

$$
F_{1}=\frac{T_{11}+T_{12} Y_{2}}{T_{21}+T_{22} Y_{2}} v_{1} .
$$

The velocity in plate 1 at the connection $v_{1}$ is assumed to be due to an incident velocity wave with amplitude $v_{a}$ at the constraint and a reflected velocity wave with amplitude at the constraint of $v_{b}$ which is generated by the force $-F_{1}$ exerted by the constraint of the connection and the second wall leaf on the first wall leaf. The reflected velocity is

$$
v_{b}=-F_{1} Y_{1}
$$

and

$$
v_{1}=v_{a}+v_{b}
$$

Solving equations (9) to (11) gives

$$
F_{1}=\frac{v_{a}}{\frac{T_{21}+T_{22} Y_{2}}{T_{11}+T_{12} Y_{2}}+Y_{1}}
$$

Equations (7) and (12) give 


$$
F_{2}=\frac{v_{a}}{Y_{t}}
$$

where the transfer admittance or mobility $Y_{t}$ is given by

$$
Y_{t}=T_{21}+T_{11} Y_{1}+T_{22} Y_{2}+T_{12} Y_{1} Y_{2}
$$

The mass law velocity $v_{m}$ in the first wall leaf forced by a plane acoustic wave with pressure amplitude $p$ incident on the first wall leaf at an angle to the normal of $\theta$ is

$$
v_{m}=\frac{2 p}{j \omega m_{1}}
$$

The factor two occurs because of pressure doubling at the hard surface of the first wall leaf.

The ratio $e$ of the resonant vibrational energy of the first wall to its mass law vibrational energy is (Crocker and Price, 1969; Cremer et al., 2005a)

$$
e=\frac{\left|v_{r 1}\right|^{2}}{\left|v_{m}\right|^{2}}=\frac{\pi \omega_{c 1} \sigma_{1}}{4 \omega \eta_{1}}=\frac{\pi f_{c 1} \sigma_{1}}{4 f \eta_{1}},
$$

where $v_{r 1}$ is the resonant velocity of the panel. At and above the critical frequency, it is not possible to distinguish between the forced response, which is given by the mass law response below the critical frequency, and the resonant response. Thus

$$
\left|v_{a}\right|^{2}=\left|v_{m}\right|^{2} Q
$$

where

$$
Q=\left\{\begin{array}{l}
1+e \text { if } \omega<\omega_{c 1} \\
e \quad \text { if } \omega \geq \omega_{c 1}
\end{array},\right.
$$

and

$$
\left|F_{2}\right|^{2}=\frac{4|p|^{2} Q}{\omega^{2} m_{1}^{2}\left|Y_{t}\right|^{2}}
$$


Because this paper is using root mean square amplitudes, the power $P_{\text {in }}$ injected into the second wall leaf by the force or force per unit length $F_{2}$ is

$$
P_{i n}=\left|F_{2}\right|^{2} l \operatorname{Re}\left(Y_{2}\right)
$$

where $l$ is equal to 1 for a point connection or is the length of the line connection.

If the area of the second wall leaf is $S$ and if its resonant mean square velocity averaged over time and over position on the second wall leaf is $\left\langle\left|v_{r 2}\right|^{2}\right\rangle$, its total vibrational energy $E$ is

$$
E=m_{2} S\left\langle\left|v_{r 2}\right|^{2}\right\rangle
$$

The rate at which energy is dissipated must be equal to the rate at which energy is injected. Thus

$$
\eta_{2} \omega m_{2} S\left\langle\left|v_{r 2}\right|^{2}\right\rangle=P_{i n}=\left|F_{2}\right|^{2} l \operatorname{Re}\left(Y_{2}\right)
$$

Hence

$$
\left\langle\left|v_{r 2}\right|^{2}\right\rangle=\frac{\left|F_{2}\right|^{2} l}{\eta_{2} \omega m_{2} S} \operatorname{Re}\left(Y_{2}\right)
$$

Therefore the power $P_{s}$ radiated by the resonant velocity of the second wall leaf is

$$
P_{s}=\rho_{0} c S \sigma_{2}\left\langle\left|v_{r 2}\right|^{2}\right\rangle=\frac{\rho_{0} c \sigma_{2}\left|F_{2}\right|^{2} l}{\eta_{2} \omega m_{2}} \operatorname{Re}\left(Y_{2}\right)
$$

where $\rho_{0}$ and $c$ are the density of air and the speed of sound in air.

Heckl (Heckl, 1959; Cremer et al., 2005b; Fahy and Gardonio, 2007) has shown that below the critical frequency, if the second wall leaf has infinite size and no other constraints, the power $P_{n}$ radiated by the vibrational field in the second wall leaf generated by the connection is

$$
P_{n}=\frac{\rho_{0}\left|F_{2}\right|^{2} l}{2 \beta m_{2}^{2}}
$$

where 


$$
\beta= \begin{cases}\pi c & \text { for a point connection } \\ \omega=2 \pi f & \text { for a line connection }\end{cases}
$$

The right hand side of equation (25) is half of the other authors' equivalent equations because this paper is using root mean square amplitudes while the other authors use peak amplitudes.

Because of its finite size and constraints, the second wall leaf also has a resonant vibrational field which occurs because of reflections at its edges and at its constraints (see equations (21) to (23)). The derivation of the expression for $P_{n}$ is only valid below the critical frequency. However $P_{n}$ is much smaller than $P_{s}$ for frequencies near the critical frequency because $\sigma_{2}$ is very much greater than $\eta_{2}$ in this frequency range. Also it is not possible to distinguish between $P_{n}$ and $P_{s}$ above the critical frequency. Thus the total power $P$ radiated by the second wall leaf due to a connection is

$$
P=P_{n} R,
$$

where

$$
R=\left\{\begin{array}{ll}
1+r & \text { if } \omega<\omega_{c 2} \\
r & \text { if } \omega \geq \omega_{c 2}
\end{array},\right.
$$

and the ratio $r$ of $P_{s}$ to $P_{n}$ is

$$
r=\frac{P_{s}}{P_{n}}=\frac{2 \sigma_{2} m_{2} c \beta \operatorname{Re}\left(Y_{2}\right)}{\omega \eta_{2}} .
$$

For a point connection (see equation (17) of Sharp (1978))

$$
Y_{2}=\frac{\omega_{c i}}{8 m_{i} c^{2}}=\operatorname{Re}\left(Y_{2}\right),
$$

and

$$
r=\frac{P_{s}}{P_{n}}=\frac{\pi \omega_{c 2} \sigma_{2}}{4 \omega \eta_{2}}=\frac{\pi f_{c 2} \sigma_{2}}{4 f \eta_{2}} .
$$

For a line connection (see equation (17) of Sharp (1978)) 


$$
Y_{i}=\frac{1-j}{4 m_{i} c} \sqrt{\frac{\omega_{c i}}{\omega}}=\frac{1-j}{4 m_{i} c} \sqrt{\frac{f_{c i}}{f}},
$$

and

$$
r=\frac{P_{s}}{P_{n}}=\frac{\sigma_{2}}{2 \eta_{2}} \sqrt{\frac{\omega_{c 2}}{\omega}}=\frac{\sigma_{2}}{2 \eta_{2}} \sqrt{\frac{f_{c 2}}{f}} .
$$

An alternative approach is that of Vigran (2010b) who numerically calculated a value of $P_{n}$ for an infinite plate with damping which is valid across the whole frequency range. Vigran's $P_{s}$ is zero because the infinite plate has no reflected waves. Below the critical frequency Vigran's $W$ is approximately equal to the $P_{n}$ used in this paper. Above the critical frequency it is approximately equal to the $P_{s}$. used in this paper.

The power $P_{0}$ incident on a unit area of the first wall is

$$
P_{0}=\frac{|p|^{2} \cos (\theta)}{\rho_{0} c},
$$

because of the use of root mean square amplitudes in this paper. If the wall has $n$ connections in a unit area, its sound transmission factor $\tau$ due to sound transmitted via the point connections is

$$
\tau(\theta)=\frac{n P}{P_{0}}=\frac{2 n \rho_{0}^{2} c Q R}{\omega^{2} m_{1}^{2} m_{2}^{2} \beta\left|Y_{t}\right|^{2} \cos (\theta)}
$$

For parallel uniformly spaced line connections, $n=1 / b$ where $b$ is the distance between the line connections.

The diffuse field sound transmission factor is

$$
\tau=2 \int_{0}^{\pi / 2} \tau(\theta) \sin (\theta) \cos (\theta) d \theta
$$

Since

$$
2 \int_{0}^{\pi / 2} \frac{\sin (\theta) \cos (\theta)}{\cos (\theta)} d \theta=2
$$


equation (35) gives

$$
\tau=\frac{4 n \rho_{0}^{2} c Q R}{\omega^{2} m_{1}^{2} m_{2}^{2} \beta\left|Y_{t}\right|^{2}} .
$$

\section{RESILIENT MASSLESS POINT CONNECTIONS}

For resilient massless point connections equation (38) becomes

$$
\tau=\frac{256 n \rho_{0}^{2} c^{4} Q R}{\pi \omega^{2}\left[\left(m_{1} \omega_{c 2}+m_{2} \omega_{c 1}\right)^{2}+64 \omega^{2} m_{1}^{2} m_{2}^{2} c^{4} C^{2}\right]} .
$$

where equations (16) and (18) are used to calculate $Q$, and equations (29) and (31) are used to calculate $R$. Changing from angular frequencies to frequencies gives

$$
\tau=\frac{16 n \rho_{0}^{2} c^{4} Q R}{\pi^{5} f^{2}\left[\left(m_{1} f_{c 2}+m_{2} f_{c 1}\right)^{2}+64 f^{2} m_{1}^{2} m_{2}^{2} c^{4} C^{2}\right]}
$$

If the properties of the two wall leaves are the same, equations (39) and (40) become

$$
\tau=\frac{64 n \rho_{0}^{2} c^{4} Q^{2}}{\pi \omega^{2} m^{2}\left[\omega_{c}^{2}+16 \omega^{2} m^{2} c^{4} C^{2}\right]},
$$

and

$$
\tau=\frac{4 n \rho_{0}^{2} c^{4} Q^{2}}{\pi f^{2} m^{2}\left[f_{c}^{2}+16 f^{2} m^{2} c^{4} C^{2}\right]} .
$$

\section{PARALLEL RESILIENT MASSLESS LINE CONNECTIONS}

Let

$$
G=m_{1} \sqrt{\omega_{c 2}}+m_{2} \sqrt{\omega_{c 1}} .
$$

For parallel resilient massless line connections equation (38) becomes

$$
\tau=\frac{64 \rho_{0}^{2} c^{3} Q R}{\left[G^{2}+\left(4 \omega^{3 / 2} m_{1} m_{2} c C-G\right)^{2}\right] b \omega^{2}},
$$


where equations (16) and (18) are used to calculate $Q$, and equations (29) and (33) are used to calculate $R$. See Davy et al. (2012) for equations for calculating $C$ for steel stud gypsum plaster board walls. Changing from angular frequencies to frequencies gives

$$
\tau=\frac{8 \rho_{0}^{2} c^{3} Q R}{\left[g^{2}+\left(8 \pi f^{3 / 2} m_{1} m_{2} c C-g\right)^{2}\right] b \pi^{3} f^{2}}
$$

where

$$
g=m_{1} \sqrt{f_{c 2}}+m_{2} \sqrt{f_{c 1}} .
$$

If the properties of the two wall leaves are the same, equations (44) and (45) become

$$
\tau=\frac{16 \rho_{0}^{2} c^{3} Q R}{\left[\omega_{c}+\left(2 \omega^{3 / 2} m c C-\sqrt{\omega_{c}}\right)^{2}\right] b m^{2} \omega^{2}},
$$

and

$$
\tau=\frac{2 \rho_{0}^{2} c^{3} Q R}{\left[f_{c}+\left(4 \pi f^{3 / 2} m c C-\sqrt{f_{c}}\right)^{2}\right] b \pi^{3} m^{2} f^{2}}
$$

A problem with equations (44) and (45) is that they are not symmetrical with regard to wall leaf number. In other words, the sound transmission factors calculated in each direction are different if the wall leaf properties are different. This occurs because only bending waves which are incident normally to the line connections have been considered. An incident bending wave in the wall leaf 1 with wave number $k_{1}$ which has an angle of incidence of $\theta_{1}$ to the normal to a line connection will have a component of wave number of $k_{1} \sin \left(\theta_{1}\right)$ parallel to the line connection. Continuity across the line connection demands that the bending waves produced in the second wall leaf must have the same wave number component parallel to the line connection. If the bending waves produced in the second wall leaf have a wave number of $k_{2}$ and have an angle of 
transmittance of $\theta_{2}$ to the normal to the line connection, they will have a component of wave number of $k_{2} \sin \left(\theta_{2}\right)$ parallel to the line connection. This means that

$$
k_{2} \sin \left(\theta_{2}\right)=k_{1} \sin \left(\theta_{1}\right) .
$$

Thus if $k_{2}<k_{1}$, total internal reflection will occur if

$$
\theta_{1}>\theta_{t}=\arcsin \left(\frac{k_{2}}{k_{1}}\right)
$$

Now

$$
\frac{k_{2}}{k_{1}}=\sqrt{\frac{\omega_{c 2}}{\omega_{c 1}}}=\sqrt{\frac{f_{c 2}}{f_{c 1}}} .
$$

Thus to avoid the effects of total internal reflection, it is necessary to number the two wall leaves such that $\omega_{c 1}<\omega_{c 2}$.

If the 1 terms in $Q$ and $R$ on the top lines of equations (44) and (45) are not significant and if $\omega_{c 1}>\omega_{c 2}$, then the total internal reflection can be accounted for by multiplying equations (44) and (45) by

$$
\sqrt{\frac{\omega_{c 2}}{\omega_{c 1}}}=\sqrt{\frac{f_{c 2}}{f_{c 1}}}=\frac{k_{2}}{k_{1}} \approx \arcsin \left(\frac{k_{2}}{k_{1}}\right)=\theta_{t} .
$$

At the other extreme, if the 1 terms in $Q$ and $R$ on the top lines of equations (44) and (45) are dominant, then the equation is already approximately symmetrical below the critical frequencies.

If $\omega_{c 1}=\omega_{c 2}$, then Heckl (personal communication) pointed out that equations (44) and (45) are still unsymmetrical if the damping loss factors and/or the resonant radiation efficiencies are different. The procedure of numbering the wall leaves based on their critical frequencies cannot resolve the problem in this situation. If it occurs, it is recommended that the average damping loss factors and radiation efficiencies be used. 
Brunskog and Chung (2011) have shown that the bending wave intensity has a maximum when the propagation direction is perpendicular to the ribs of a ribbed panel. Presumably this is due to the bending stiffness and mass of the ribs. This may explain why the assumption of the bending waves being incident normally to the line connections works better than might be expected. Some unpublished calculations by the author have shown that the transmission of bending wave energy from one wall leaf to another via a line connection without bending stiffness does not vary greatly with the angle of incidence to the line connection providing the angle of incidence is less than the angle at which total internal reflection occurs. These calculations would also explain why the assumption of normal incidence appears to work reasonably well.

\section{COMPARISON WITH MEASUREMENTS}

Quirt and Warnock (1993) have shown that the sound insulation of wooden stud walls is strongly dependent on the screw spacing while the sound insulation of steel stud walls only varies slightly with screw spacing. Thus it may be that the line connection theory is adequate for steel stud walls, if suitable a stud compliance as a function of frequency can be determined (Davy et al., 2012). Hence, in this paper, a comparison will be made with the NRCC (Halliwell et al., 1998) experimental results for wooden stud gypsum plaster board cavity walls where the gypsum plaster board is connected to the wooden studs by screws. Eight wooden stud results were found in the NRCC results. All the results were for test specimen walls having $90 \mathrm{~mm}$ wooden studs at $406 \mathrm{~mm}$ centres and sound absorbing material in the cavity. Three of the walls had blown cellulose fibre and the other five had mineral fibre in their cavities. Six of the walls were constructed from fire-rated (X) gypsum plaster board and the other two were constructed from ordinary gypsum plaster board. The results for walls which only differed in the type of 
plasterboard or the type of sound absorbing material in their cavities were combined and averaged in the decibel domain. This resulted in five different classes of wall. These were 13-90406W (3 measurements), 13(13+13)-90-406W (2 measurements), 13+13-90-406W (1 measurement), 16-90-406W (1 measurement) and 16(16+16)-90-406 (1 measurement). The 90 denotes the width of the studs in mm and cavity, the 406 denotes the spacing of the studs in mm and the $\mathrm{W}$ denotes wooden studs. The first number denotes the thickness of the gypsum plaster board on each side of the studs in mm. If the thicknesses are different on each side of the studs, the second thickness is given in $\mathrm{mm}$ in brackets after the first thickness. If multiple layers of gypsum plaster board are used on one or both sides of the wooden studs, their thicknesses in mm are separated by plus sign(s).

The single and face layers of gypsum plaster board were attached to the wooden studs with screws based $406 \mathrm{~mm}$ part along the length of the studs. The base layers were attached with screws at $610 \mathrm{~mm}$ apart. The theoretical model used a stud spacing of $406 \mathrm{~mm}$. The compliance $C$ of both the point and line connections in the theoretical model is assumed to be zero in order to model the rigid wooden studs. The NRCC report gives the actual mass per unit area of the gypsum plaster board. Because of the combination of different types of gypsum plaster board into the same class, gypsum plaster board is assumed to have a density of $770 \mathrm{~kg} / \mathrm{m}^{2}$ in this paper and the nominal thickness of the gypsum plaster board is used with this density to calculate the mass per unit area. The sound absorption coefficient of the cavity sound absorbing material is assumed to be 1 . Note that Davy's (2009) theory for airborne transmission via the wall cavity limits the actual value of the sound absorbing material at low frequencies depending on the width of the cavity. 
A single layer of gypsum plaster board is assumed to have a Young's modulus of 2.2 GPa. Because two layers of gypsum plaster board on one side of the wooden studs are only fastened at points by the screws, they can slide relative to each other when being bent by the sound. The result is that the critical frequency of two equal thicknesses of gypsum plaster board is almost the same as that of a single thickness. In the theoretical results of this paper this result is achieved by assuming that two thicknesses behave as a single thickness of the same total thickness with a Young's modulus of approximately one quarter of one of the original single layers. In this paper two layers of gypsum plaster board are assumed to have a Young's modulus of $0.6 \mathrm{GPa}$. The Poisson's ratio of gypsum plaster board is assumed to be 0.3 .

The in-situ damping loss factor of gypsum plaster board is assumed to be 0.03 . The insitu damping loss factors have a significant effect on the theory for air borne sound transmission across the cavity above the critical frequency but only have a small effect below the critical frequency. However the theory for structure borne transmission across the cavity is affected by the in-situ damping loss factors across the whole frequency range. It should be noted that there is some evidence that the damping loss factor of materials may vary with frequency (Hongisto, 2001). It is possible that the use of double layers of gypsum plaster board on one or both sides of the studs may introduce more damping and increase the damping loss factor.

The stud borne transmission across the cavity is combined with the airborne transmission across the cavity calculated using the latest version of the author's theory (Davy, 2010). The stud borne transmission is not included in the combined transmission below the mass-air-mass resonance frequency. In this frequency range, the wall leaves are already effectively coupled by the air cavity. The corrected versions of Maidanik's formulae for the single sided radiation efficiency of a freely propagating reverberant bending wave vibration field given by Vér and 
Holmer (1971) are used in this paper. However the maximum value of the radiation efficiency is limited to the value one.

Figures 1 to 5 show the comparison of the theory with experiment. The experimental results are denoted by "experiment", the airborne transmission across the cavity by "studless_stl", the line connection transmission by "stud_stl", and the point connection transmission by "point_stl". The combination of the airborne transmission with the line or point transmission is denoted by "combostud" or "combopt" respectively. Above $200 \mathrm{~Hz}$, the agreement with the "combopt" predictions is reasonable. Although, between 200 and $2000 \mathrm{~Hz}$, there is a clear trend for the "experiment" values to move from greater relative to the "combopt" values to smaller than the "combopt" values as the thickness and number of the gypsum plaster board sheets increases.

There is a deep dip in the "experiment" results relative to the theoretical results in the 100 to $200 \mathrm{~Hz}$ range. Bradley and Birta (2001b) point out that a rigid connection between the wall leaves effectively moves the mass-air-mass resonance to the frequency of the structural resonance. Bradley and Birta (2001a) have shown that the sound insulation of wood stud exterior walls can be significantly degraded by a structural resonance if the two wall leaves are rigidly coupled by the wooden studs. They explain this structural resonance in terms of the analysis conducted by Lin and Garrelick (1977). The effects of this resonance can be reduced by structurally isolating the two wall leaves with resilient mounts, thin steel studs, staggered studs or double studs. The frequency of the resonance is about double the calculated mass-air-mass resonance and it reduces in frequency as the rigid stud spacing is increased and as the depth of the rigid studs is increased. 
Bradley and Birta (2000) report the results of laboratory sound insulation measurements on typical Canadian building facades. These measurements showed the structural resonance at $125 \mathrm{~Hz}$. However field measurements with actual aircraft noise showed little effect due to this structural resonance. The theory presented in this paper cannot predict this structural resonance but it may not be important in actual field application. In order to predict this structural resonance, a fully coupled theory like that of Lin and Garrelick (1977), Takahashi (1983) or Brunskog (2005) would need to be used.

The "combostud" values under predict the sound insulation above $200 \mathrm{~Hz}$, although there is a tendency for the "experiment" values to move towards the "combostud" values in the 400 to $2000 \mathrm{~Hz}$ range as the thickness and number of the gypsum plaster board sheets increases. As mentioned in the introduction, Davy (2010) forced the "combostud" values to agree reasonably well with the NRCC "experiment" values by using an unrealistically high value of damping loss factor of 0.1 .

Figure 6 shows the effect of changing the damping loss factor on the theoretical predictions of the total sound insulation ("combopt" in Figure 3) of two layers of $13 \mathrm{~mm}$ of gypsum plaster board screwed on each side of wooden studs with sound absorbing material in the cavity $(13+13-90-406 \mathrm{~W})$. Unlike the studless predictions which are only effected by the damping loss factor above about half the critical frequency, the point and line connection predictions are effected above the normal incidence mass-air-mass resonance, which occurs at 62 $\mathrm{Hz}$ for the predictions shown in Figure 6. In this frequency range, the sound insulation increases when the damping loss factor increases. Comparison with the experimental results shows that allowing the damping loss factor to vary as a function of frequency could produce better agreement. 


\section{CONCLUSIONS}

The full derivation of the author's theory for predicting the airborne sound transmission of double leaf cavity walls due to the structure borne sound transmission via point or line connections which are modelled as four pole networks has been presented. The rigid point connection model gives reasonable predictions of the sound insulation of wooden stud gypsum plaster board cavity walls with sound absorbing material in the cavity, apart from failing to predict the deep dip in the 100 to $200 \mathrm{~Hz}$ frequency range. The rigid line connection model predicts sound insulation values which are lower than the experimental values above $200 \mathrm{~Hz}$ unless unrealistically high values of damping loss factor are used.

\section{REFERENCES}

Bradley, J. S., and Birta, J. A. (2000). "Laboratory measurements of the sound insulation of building façade elements," in Institute for Research in Construction Internal Report IRC IR-818 (National Research Council of Canada, Ottawa), p. 183.

Bradley, J. S., and Birta, J. A. (2001a). "On the sound insulation of wood stud exterior walls," J. Acoust. Soc. Am. 110, 3086-3096.

Bradley, J. S., and Birta, J. A. (2001b). "A simple model of the sound insulation of gypsum board on resilient supports," Noise Control Eng. J. 49, 216-223.

Brunskog, J. (2005). "The influence of finite cavities on the sound insulation of double-plate structures," J. Acoust. Soc. Am. 117, 3727-3739.

Brunskog, J., and Chung, H. (2011). "Non-diffuseness of vibration fields in ribbed plates," J. Acoust. Soc. Am. 129, 1336-1343. 
Campolina, B., Atalla, N., Dauchez, N., and Neple, P. (2012). "Four-pole modelling of vibration isolators: application to SEA of aircraft double-wall panels subjected to mechanical excitation," Noise Control Eng. J. 60, 158-170.

Craik, R. J. M., and Smith, R. S. (2000a). "Sound transmission through double leaf lightweight partitions part I: airborne sound," Appl. Acoust. 61, 223-245.

Craik, R. J. M., and Smith, R. S. (2000b). "Sound transmission through lightweight parallel plates. Part II: structure-borne sound," Appl. Acoust. 61, 247-269.

Cremer, L., Heckl, M., and Petersson, B. A. T. (2005a). "7.8.5 Transmission loss in the vicinity of the critical frequency," in Structure-borne sound - Structural vibrations and sound radiation at audio frequencies (Springer-Verlag, Berlin), pp. 524-525.

Cremer, L., Heckl, M., and Petersson, B. A. T. (2005b). "Section 7.6.4 Radiation from externally excited bending waves," in Structure-borne sound - Structural vibrations and sound radiation at audio frequencies (Springer-Verlag, Berlin), pp. 492-497.

Crocker, M. J., and Price, A. J. (1969). "Sound transmission using statistical energy analysis," J. Sound Vib. 9, 469-486.

Davy, J. L. (1990a). "A model for predicting the sound transmission loss of walls," in The Australian Vibration and Noise Conference 1990, National Conference Publication No. 90/9 (The Institution of Engineers, Australia, Melbourne), pp. 23-27.

Davy, J. L. (1990b). "Predicting the sound transmission loss of cavity walls," in Interior noise climates: National Conference of the Australian Acoustical Society (Perth, W.A.), pp. 17.11-17.16.

Davy, J. L. (1991). "Predicting the sound insulation of stud walls," in Costs of Noise: Proceedings of Inter-Noise 91 Conference (Sydney, N.S.W.), pp. 251-254. 
Davy, J. L. (1993). "The sound transmission of cavity walls due to studs," in Inter-noise 93: International Conference on Noise Control Engineering (Leuven, Belgium), pp. 975-978.

Davy, J. L. (2009). "Predicting the sound insulation of walls," Build. Acoust. 16, 1-20.

Davy, J. L. (2010). "The improvement of a simple theoretical model for the prediction of the sound insulation of double leaf walls," J. Acoust. Soc. Am. 127, 841-849.

Davy, J. L., Guigou-Carter, C., and Villot, M. (2012). "An empirical model for the equivalent translational compliance of steel studs," J. Acoust. Soc. Am. 131, Accepted 20 April 2012.

Fahy, F., and Gardonio, P. (2007). "3.10 Sound radiation due to concentrated forces and displacements," in Sound and structural vibration : radiation, transmission and response (Elsevier, Amsterdam), pp. 195-204.

Halliwell, R. E., Nightingale, T. R. T., Warnock, A. C. C., and Birta, J. A. (1998). "Gypsum board walls: transmission loss data," in Internal Report IRC-IR-761 (Institute for Research in Construction, National Research Council of Canada, Ottawa, Canada), pp. 1368.

Heckl, M. (1959). "Schallabstralung von Platten bei Punktförmiger Anregung (Sound radiation from plates with point excitation)," Acust. 9, 371-380.

Hongisto, V. (2001). "Case study of flanking transmission through double structures," Appl. Acoust. 62, 589-599.

Legault, J., and Atalla, N. (2009). "Numerical and experimental investigation of the effect of structural links on the sound transmission of a lightweight double panel structure," J. Sound Vib. 324, 712-732. 
Legault, J., and Atalla, N. (2010). "Sound transmission through a double panel structure periodically coupled with vibration insulators," J. Sound Vib. 329, 3082-3100.

Lin, G. F., and Garrelick, J. M. (1977). "Sound-transmission through periodically framed parallel plates," J. Acoust. Soc. Am. 61, 1014-1018.

Quirt, J. D., and Warnock, A. C. C. (1993). "Influence of sound-absorbing material, stud type and spacing, and screw spacing on sound transmission through a double-panel wall specimen," in Inter-Noise 93 - People Versus Noise, Vols 1-3, edited by P. Chapelle, and G. Vermeir, pp. 971-974.

Sharp, B. H. (1973). "A study of techniques to increase the sound insulation of building elements," in Wyle Laboratories Report WR 73-5, Wyle Laboratories Research Staff, El Segundo, California, distributed as PB-222 829, National Technical Information Service, United States Department of Commerce, Springfield, Virginia., pp. 1-227.

Sharp, B. H. (1978). "Prediction Methods for the Sound Transmission of Building Elements," Noise Control Engineering 11, 53-63.

Sharp, B. H., Kasper, P. K., and Montroll, M. L. (1980). "Sound Transmission through Building Structures - Review and Recommendations for Research," in NBS-GCR-80-250, National Bureau of Standards, United States Department of Commerce, Washington, D. C., . Distributed as PB81-187072, National Technical Information Service, United States Department of Commerce, Springfield, Virginia, pp. 1-147.

Takahashi, D. (1983). "Sound radiated from periodically connected double-plate structures," J. Sound Vib. 90, 541-557.

Vér, I. L. (1971). "Impact noise insulation of composite floors," J. Acoust. Soc. Am. 50, 10431050. 
Vér, I. L., and Holmer, C. I. (1971). "Interaction of sound waves with solid structures," in Noise and Vibration Control, edited by L. L. Beranek (McGraw-Hill, New York), pp. 270-361.

Vigran, T. E. (2010a). "Sound insulation of double-leaf walls - allowing for studs of finite stiffness in the transfer matrix scheme," Appl. Acoust. 71, 616-621.

Vigran, T. E. (2010b). "Sound transmission in multilayered structires - Introducing finite structural connections in the transfer matrix method," Appl. Acoust. 71, 39-44.

Wang, J., Lu, T. J., Woodhouse, J., Langley, R. S., and Evans, J. (2005). "Sound transmission through lightweight double-leaf partitions: theoretical modelling," J. Sound Vib. 286, 817-847.

\section{FIGURE CAPTIONS}

Figure 1. Comparison of the theoretical and the experimental (Halliwell et al., 1998) sound insulation for $13 \mathrm{~mm}$ of gypsum plaster board on each side of wooden studs with sound absorbing material in the cavity $(13-90-406 \mathrm{~W})$. (Colour online)

Figure 2. Comparison of the theoretical and the experimental (Halliwell et al., 1998) sound insulation for $13 \mathrm{~mm}$ of gypsum plaster board on one side of wooden studs with sound absorbing material in the cavity and two layers of $13 \mathrm{~mm}$ gypsum plaster board on the other side (13(13+13)-90-406W). (Colour online)

Figure 3. Comparison of the theoretical and the experimental (Halliwell et al., 1998) sound insulation for two layers of $13 \mathrm{~mm}$ of gypsum plaster board on each side of wooden studs with sound absorbing material in the cavity $(13+13-90-406 \mathrm{~W})$. (Colour online) 
Figure 4. Comparison of the theoretical and the experimental (Halliwell et al., 1998) sound insulation for $16 \mathrm{~mm}$ of gypsum plaster board on each side of wooden studs with sound absorbing material in the cavity (16-90-406W). (Colour online)

Figure 5. Comparison of the theoretical and the experimental (Halliwell et al., 1998) sound insulation for $16 \mathrm{~mm}$ of gypsum plaster board on one side of wooden studs with sound absorbing material in the cavity and two layers of $16 \mathrm{~mm}$ gypsum plaster board on the other side $(16(16+16)-90-406 \mathrm{~W}) .($ Colour online $)$

Figure 6 . The effect of changing the damping loss factor on the theoretical predictions of the total sound insulation ("combopt" in Figure 3) of two layers of $13 \mathrm{~mm}$ of gypsum plaster board screwed on each side of wooden studs with sound absorbing material in the cavity $(13+13-90$ 406W). These predictions are compared with the experimental values. (Colour online) 


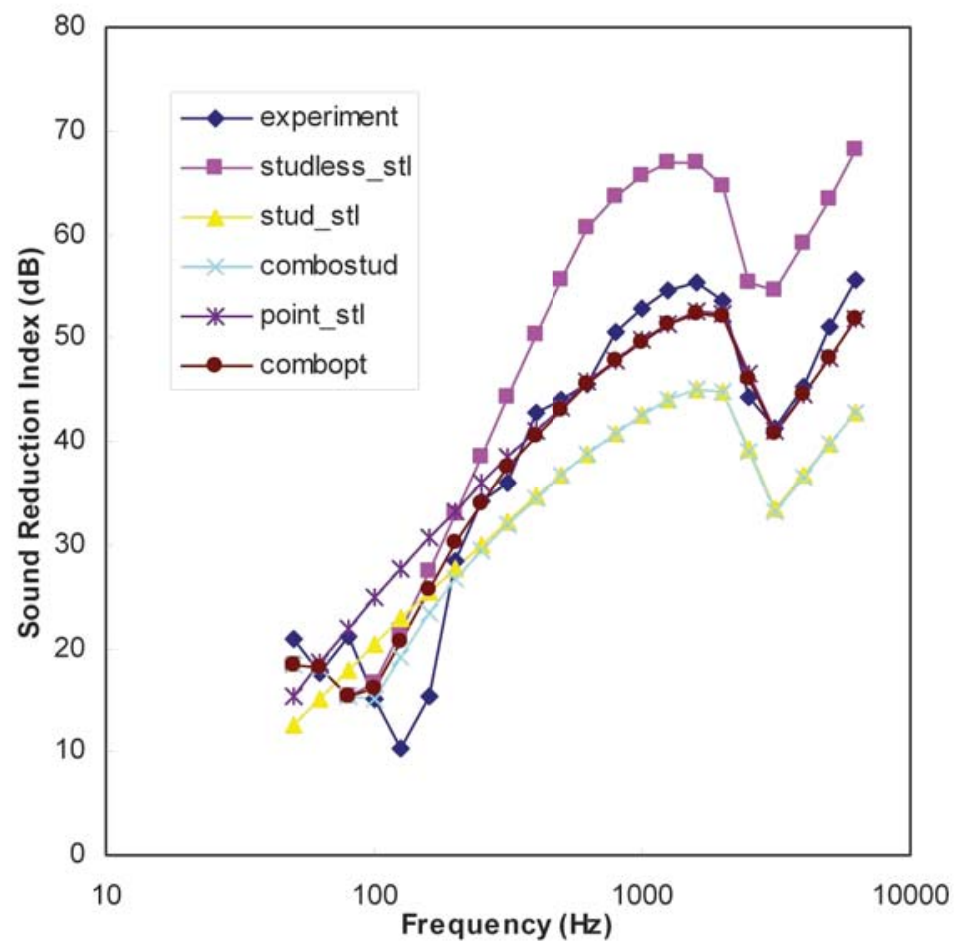




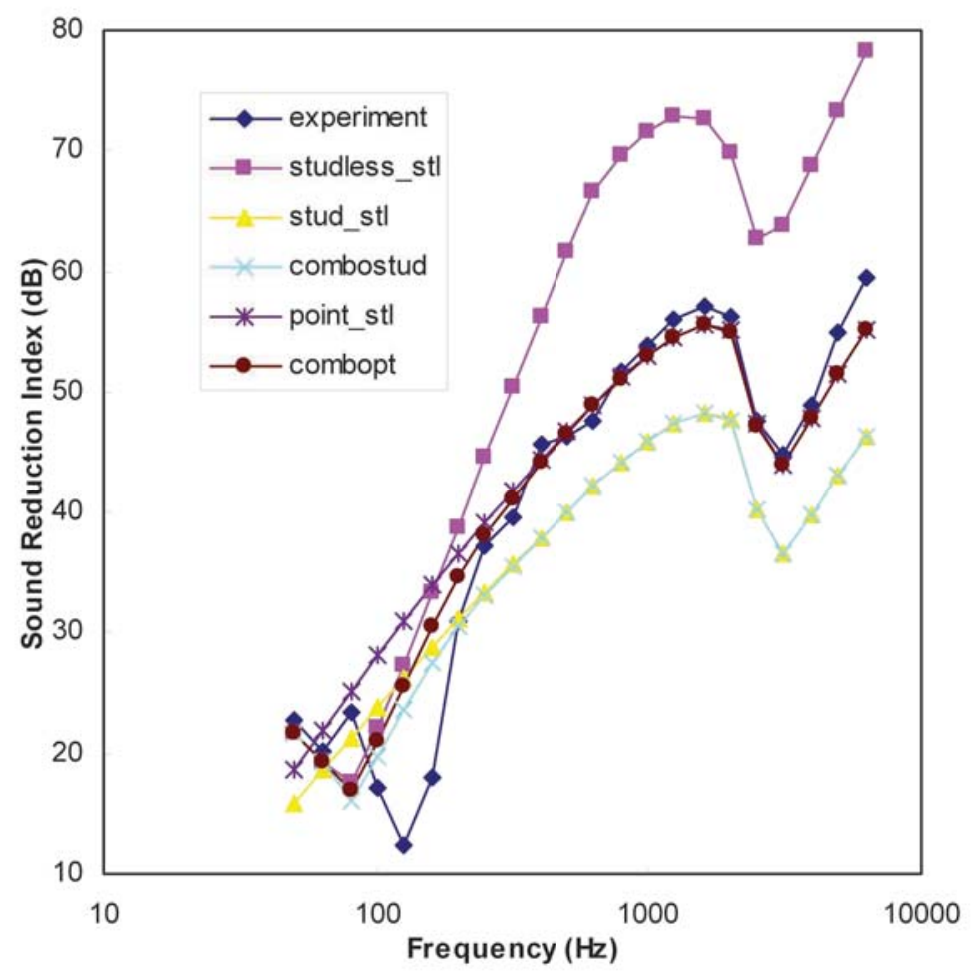




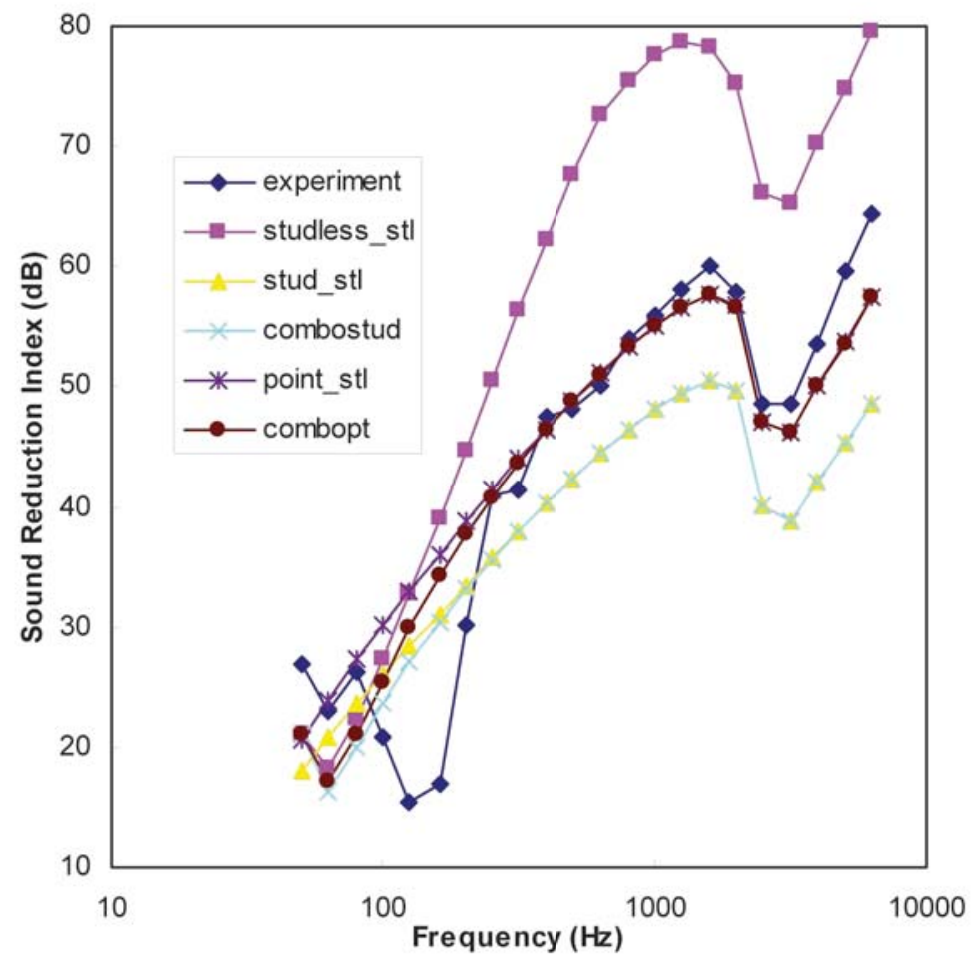




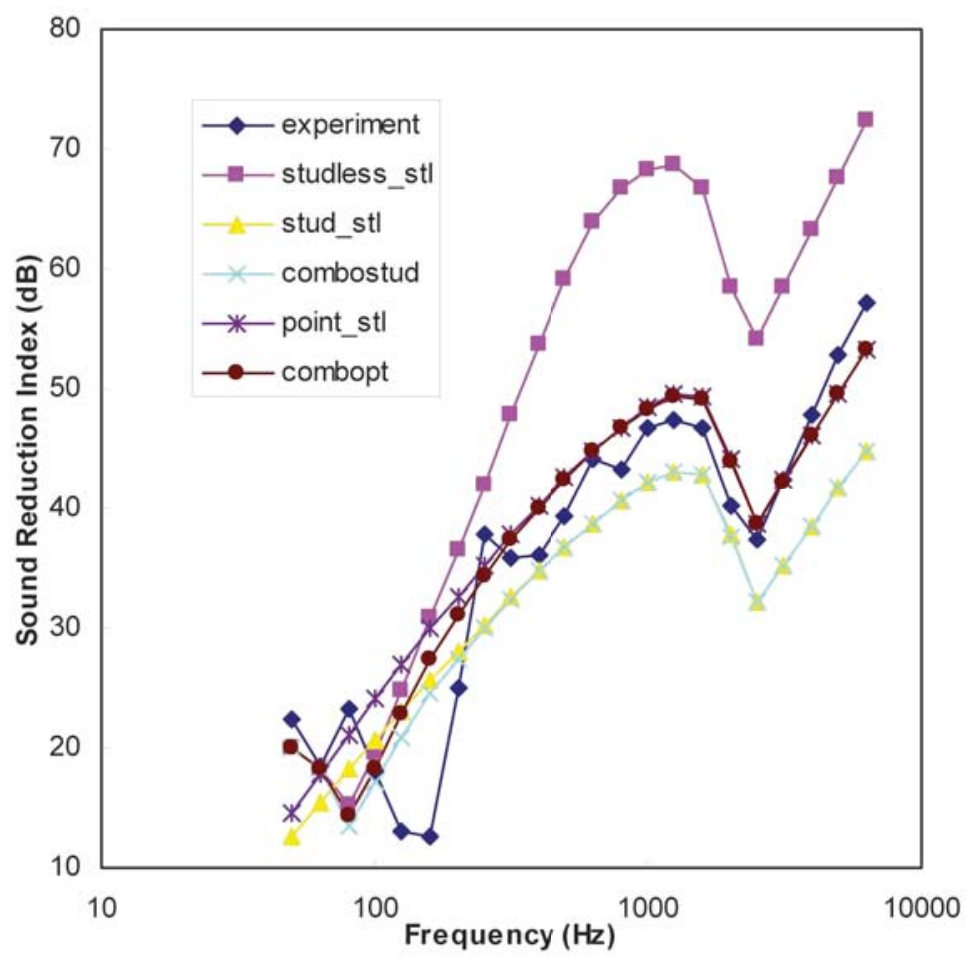




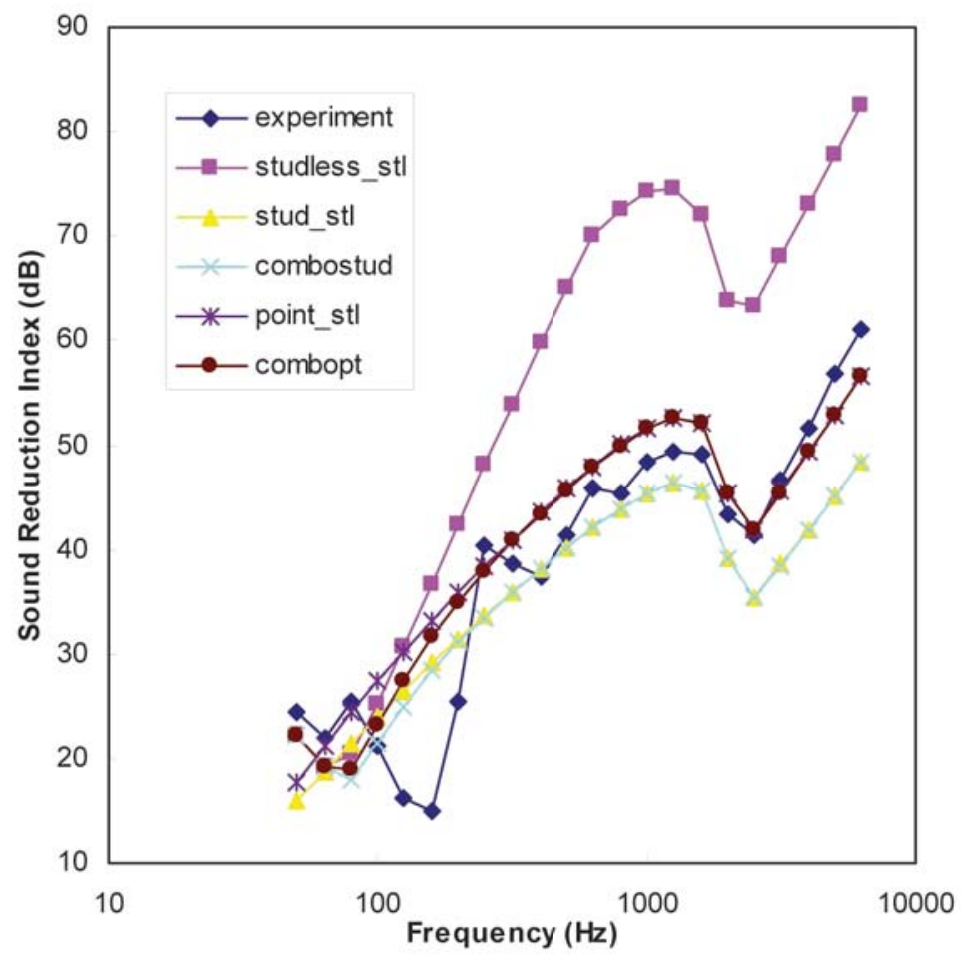




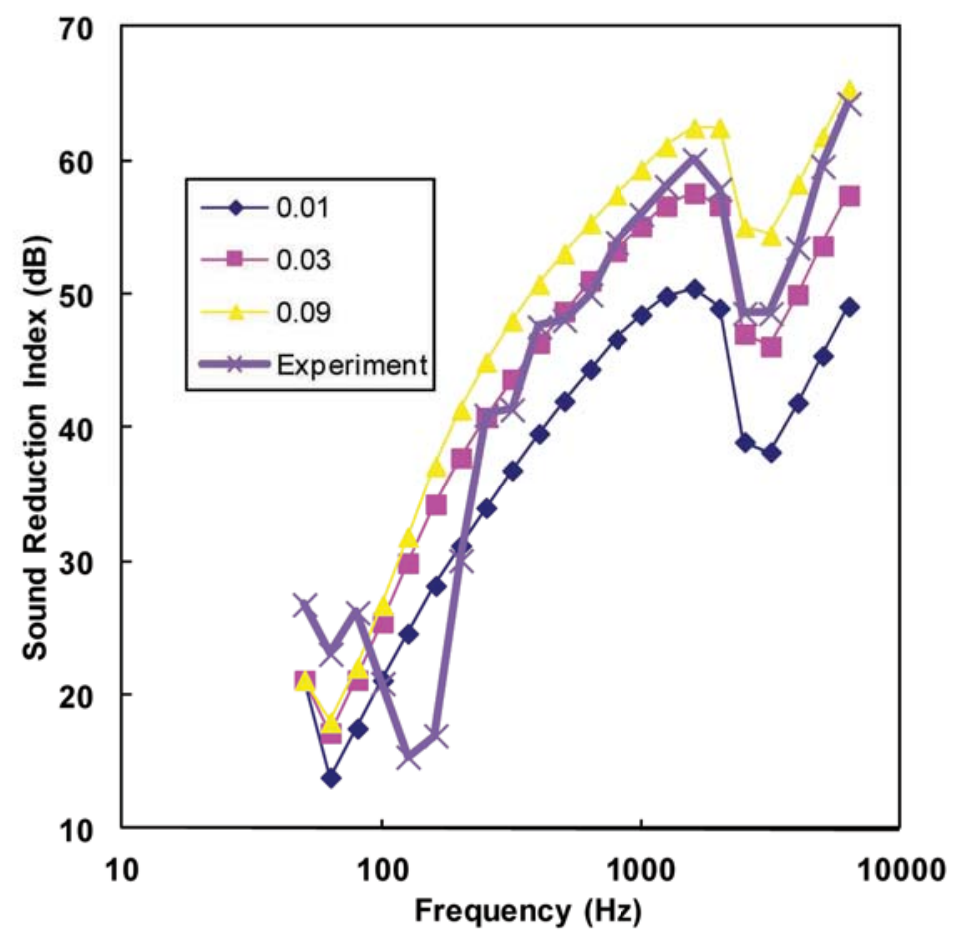

